\title{
Impact of Education on COPD Severity and All-Cause Mortality in Lifetime Never-Smokers and Longtime Ex-Smokers: Results of the COSYCONET Cohort
}

This article was published in the following Dove Press journal:

International Journal of Chronic Obstructive Pulmonary Disease

\begin{abstract}
Johanna I Lutter, (D)' Rudolf A Jörres, (iD) ${ }^{2}$ Tobias Welte, (iD) ${ }^{3}$ Henrik Watz, ${ }^{4}$ Benjamin Waschki, (iD ${ }^{5}$ Peter Alter, (ID ${ }^{6}$ Franziska C Trudzinski, (ID) Johan Ohlander, ${ }^{1,8}$ Jürgen Behr, ${ }^{9}$ Robert Bals, ${ }^{10}$ Michael Studnicka, (D) ${ }^{11}$ Rolf Holle, (iD ${ }^{12}$ Claus F Vogelmeier, 6 Kathrin Kahnert ${ }^{9}$
\end{abstract}

IInstitute of Health Economics and Health Care Management, Helmholtz Zentrum München GmbH German Research Center for Environmental Health, Comprehensive Pneumology Center Munich (CPC-M), Member of the German Center for Lung Research, Munich, Germany; ${ }^{2}$ Institute and Outpatient Clinic for

Occupational, Social and Environmental Medicine, Comprehensive Pneumology Center Munich (CPC-M), Ludwig-Maximilians-Universität München, Munich 80336, Germany; ${ }^{3}$ Department of Pneumology, Hannover Medica School, Hannover 30625, Germany; ${ }^{4}$ Pulmonary Research Institute at Lungen Clinic Grosshansdorf, Airway Research Center North (ARCN), Member of the German Center for Lung Research (DZL), Grosshansdorf 22927, Germany; ${ }^{5}$ Department of General and Interventional Cardiology, University Heart Center Hamburg, Hamburg, Germany; ${ }^{6}$ Department of Medicine, Pulmonary and Critical Care Medicine, University Medical Center Giessen and Marburg. Philipps-University Marburg (UMR), Germany, Member of the German Center for Lung Research (DZL), Marburg 35043, Germany; ${ }^{7}$ Department of Diagnostic \& Interventional Radiology, University Hospital of Heidelberg. Heidelberg, Germany; ${ }^{8}$ Institute for Risk Assessment Sciences, Utrecht University, Utrecht 3584 CM, Netherlands; 'Department of Internal Medicine $V$, University of Munich (LMU), Comprehensive Pneumology Center, Member of the German Center for Lung Research (DZL), Munich, 80336, Germany; ${ }^{10}$ Department of Internal Medicine V - Pulmonology, Allergology, Respiratory Intensive Care Medicine, Saarland University Hospita Homburg 66424, Germany; " Department of Pneumology, Paracelsus Medical University Salzburg,

Universitätsklinikum Salzburg, Salzburg 5020, Austria; ${ }^{12}$ Institute for Medical Informatics, Biometry and Epidemiology, University Hospital Ludwig-MaximiliansUniversity Munich (LMU), Munich 81377, Germany

Correspondence: Kathrin Kahnert Department of Internal Medicine V, University of Munich (LMU), Comprehensive Pneumology Center, Member of the German Center for Lung Research (DZL), Ziemssenstr. I, Munich 80336, Germany

Email Kathrin.Kahnert@med.uni-muenchen.de
Background: Beyond smoking, several risk factors for the development of chronic obstructive pulmonary disease (COPD) have been described, among which socioeconomic status including education is of particular interest. We studied the contribution of education to lung function and symptoms relative to smoking in a group of never-smokers with COPD compared to a group of long-time ex-smokers with COPD.

Methods: We used baseline data of the COSYCONET cohort, including patients of GOLD grades 1-4 who were either never-smokers ( $\mathrm{n}=150$, age $68.5 \mathrm{y}, 53.3 \%$ female) or ex-smokers ( $\geq 10$ packyears) for at least 10 years $(n=616,68.3 y, 29.9 \%$ female). Socioeconomic status was analyzed using education level and mortality was assessed over a follow-up period of 4.5 years. Analyses were performed using ANOVA and regression models.

Results: Spirometric lung function did not differ between groups, whereas CO diffusing capacity and indicators of lung hyperinflation/air-trapping showed better values in the neversmoker group. In both groups, spirometric lung function depended on the education level, with better values for higher education. Quality of life and 6-MWD were significantly different in never-smokers as well as patients with higher education. Asthma, alpha-1-antitrypsin deficiency, and bronchiectasis were more often reported in never-smokers, and asthma was more often reported in patients with higher education. Higher education was also associated with reduced mortality (hazard ratio 0.46 ; 95\% CI $0.22-0.98$ ).

Conclusion: Overall, in the COSYCONET COPD cohort, differences in functional status between never-smokers and long-time ex-smokers were not large. Compared to that, the dependence on education level was more prominent, with higher education associated with better outcomes, including mortality. These data indicate that non-smoking COPD patients' socioeconomic factors are relevant and should be taken into account by clinicians.

Keywords: COPD, never-smoker, education, socioeconomic status

\section{Introduction}

Smoking is considered the major risk factor for COPD. Consequently for the last decades, there has been only minimal scientific interest in COPD in never-smokers. However, data from NHANES III describe, that $6.6 \%$ of participants with a spirometric diagnosis of COPD were in fact never-smokers. ${ }^{1}$ Other population-based data including the international BOLD survey even demonstrated a never-smoking proportion among COPD of up to $23 \%$. $^{2,3}$ Several other risk factors for COPD beyond smoking 
have been described. More than $80 \%$ of households in China, India and sub-Saharan Africa use biomass for cooking, and in rural areas of Latin America this proportion ranges between $30 \%$ and $75 \%$, with a significant impact on death from COPD. ${ }^{4}$ In industrialized countries other COPD risk factors like workplace exposures, ${ }^{2,3}$ recurrent lower respiratory tract infections, low birth weight, bronchial asthma, history of tuberculosis $^{5-7}$ and low socioeconomic status ${ }^{8}$ have been identified. As early as 1987, a comparative analysis of Finnish farmers and non-farmers showed that a higher proportion of farmers $(2-7 \%)$ than non-farmers $(0-7 \%)$ had COPD, independent of smoking ${ }^{9}$ and has been replicated since then. ${ }^{3}$ The relative contribution of these factors may differ from country to country, particularly regarding socioeconomic status. $^{10}$

A proper population for comparison might be patients with exposure to a definite risk factor over a sufficient period of time, which has stopped, so that acute, potentially disturbing effects are no more present. This could be ex-smokers for a long time with a certain minimum amount of smoking. Both groups are exposed to socioeconomic risk factors but one of them has an additional exposure known to affect lung function, symptoms and prognosis. By this comparison the contribution from socioeconomic status including education can be analysed, as well as their possible differences to and interactions with cigarette smoking. This type of analysis requires a sufficiently large set of data including both neversmokers and long-time ex-smokers measured under the same conditions. Such data are available in the large and wellcharacterized COPD cohort COSYCONET (COPD and Systemic Consequences-Comorbidities Network).

\section{Methods}

\section{Study Population}

The present analysis used the baseline data (visit 1) of the COPD cohort COSYCONET $(n=2741)$, which is a multicenter study focusing on the role of comorbidities in COPD. ${ }^{1}$ Out of 2291 patients with COPD GOLD grades 1-4, 150 patients were identified as never-smokers based on selfreports of smoking behaviour (packyears $=0$, no active cigarette smoking over lifetime). The group of ex-smokers used for comparison included $\mathrm{n}=616$ patients and was defined as patients who had stopped smoking for at least 10 years and had a smoking history of $\geq 10$ packyears (Figure 1). Further information on the recruitment process and inclusion/exclusion criteria can be found elsewhere. ${ }^{1}$ The COSYCONET study has been approved by the ethical committees of all study centers, and all patients gave their written informed consent. ${ }^{1}$ The COSYCONET study was conducted in accordance with the Declaration of Helsinki.

\section{Assessments}

Demographic characteristics, socioeconomic variables and the prevalence of comorbidities were assessed based on measurements, questionnaires and standardized interviews. Education was categorized in three groups based on the number of years of education completed (basic education $\leq 9$ years, secondary education 10 to 11 years, higher education $>11$ years). Household equivalent income was calculated as the net household income per month divided by the number of persons living in the household weighted by age groups. $^{2}$ The presence of comorbidities was determined based on patients' reports of physician-based diagnoses, including data on the intake of disease-specific medication. ${ }^{3}$ Patients were asked to bring all their medication to the study visit, which was categorized as previously described. ${ }^{3,4}$

Lung function was assessed following the standard operating procedures of COSYCONET, which align with guidelines. $^{5,6}$ It included forced expiratory volume in one second $\left(\mathrm{FEV}_{1}\right)$, forced vital capacity (FVC) and their ratio $\left(\mathrm{FEV}_{1} / \mathrm{FVC}\right)$, moreover diffusing capacity for carbon monoxide (CO) in terms of transfer factor (TLCO), transfer coefficient (KCO) and alveolar volume (VA). Bodyplethysmographic parameters included intrathoracic gas volume (ITGV), residual volume (RV), total lung capacity (TLC) and the ratio of residual volume to total lung capacity (RV/TLC). For spirometry, we used predicted values provided by the Global Lung Function Initiative (GLI), ${ }^{6}$ analogously for TLCO and KCO. ${ }^{7}$ Predicted values for body plethysmography were taken from Quanjer et al. ${ }^{8}$ Physical capacity was assessed via the Six Minute Walking Distance (6-MWD), timed-up-and -go test (TUG), and the International Physical Activity Questionnaire (IPAQ) ${ }^{9}$. Vascular function was quantified via the ankle-brachial index (ABI). ${ }^{1,10}$ Measures of healthrelated quality of life (HRQL) included the diseasespecific COPD Assessment Test (CAT) and the Saint George's Respiratory Questionnaire for COPD patients (SGRQ) $^{11}$ with its three components activity, symptoms, and impacts. To capture generic HRQL, we used the Euroqol 5D 3L utility index and the visual analog scale (EQ VAS). ${ }^{12}$

Using the data from follow-up visits, we also examined all-cause mortality over 4.5 years. The survival status was 
assessed by contacting partners, relatives, primary care practitioners and hospitals. ${ }^{13}$

\section{Statistical Analyses}

Regarding baseline characteristics of never-smokers and ex-smokers, differences between groups were identified using chi-square tests for categorical variables, and analysis of variance (ANOVA) for continuous variables. To estimate mean values stratified by smoking status and the level of education, we performed multiple ANOVA models. Models were adjusted for age, sex, body mass index (BMI), years since COPD diagnosis and an interaction between smoking status and education. We repeated this analysis excluding all patients with a confirmed physicianbased diagnosis of asthma.

The association of comorbidities and medication with smoking status and education was analysed with logistic regression models, while we used proportional hazard Cox regression analysis for mortality. Models were adjusted for age, sex, and BMI and the presence of coronary artery disease. We additionally included $\mathrm{FEV}_{1 \%}$ predicted in the analysis of medication and mortality to account for the severity of the disease.

A sensitivity analysis was performed to determine the robustness of our results while modifying the definition of the group of ex-smokers. For this purpose, three subgroups of ex-smokers were formed based on the number of years since cessation of smoking (10-15 years, $16-25$ years, $>25$ years). Statistical analyses were performed using SAS software
(SAS Institute Inc., Cary, NC, USA, version 9.4), and p-values of $\leq 0.05$ were considered statistically significant.

\section{Results \\ Study Population}

Baseline characteristics of patients are given in Table 1. Within ex-smokers, the mean smoking free interval was 19.3 years $(\mathrm{SD} \pm 9.2$ ). Among non-smokers, the proportion of women was significantly higher; they also showed significantly better lung function in terms of $\mathrm{FEV}_{1} / \mathrm{FVC}$, TLCO, $\mathrm{KCO}$ and TLC. In addition, a longer-lasting diagnosis of COPD was found in never-smokers. Regarding physical capacity, never-smokers walked 29 meters more than ex-smokers did in the 6MWD test, while we found no differences in TUG and IPAQ. There were also no significant differences between never- and exsmokers in terms of educational level, COPD symptoms, PHQ9 and health-related quality of life.

The household net income per months was significantly associated with the level of education and mean income was $1153 €$ for patients with basic education, $1360 €$ for secondary education and $1684 €$ for higher education (Table 2).

\section{Relationship Between Outcome Variables, Smoking Status and Educational Level}

Multiple linear regression analysis revealed that educational level was associated with $\mathrm{FEV}_{1}, \mathrm{FVC}, \mathrm{FEV}_{1} / \mathrm{FVC}$,

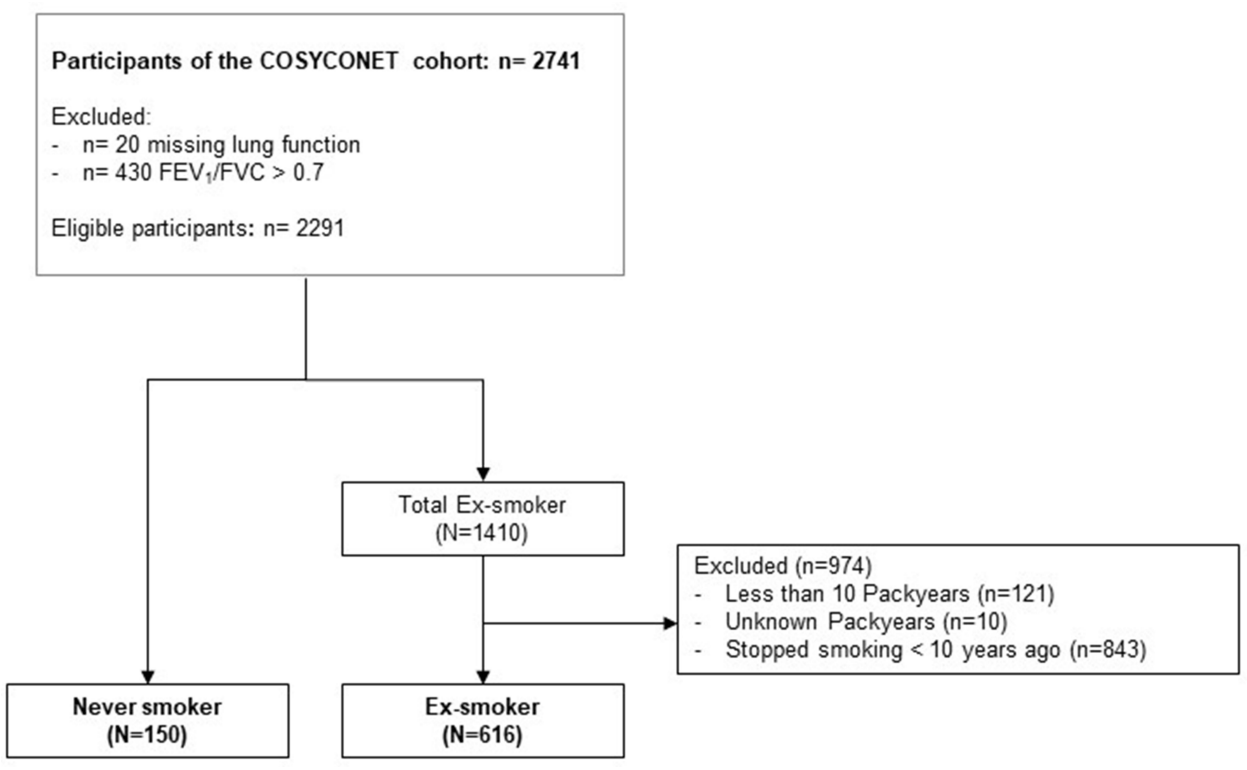

Figure I Consort diagram of the study population. 
RV/TLC, TLC, 6-MWD, TUG, the total SGRQ and its activity component, as well as EQ-VAS $(p<0.05$ each, Table 3). Smoking status was associated with $\mathrm{FEV}_{1} / \mathrm{FVC}$, ITGV, RV, TLCO, KCO, 6-MWD and the activity component of the SGRQ $(p<0.05$ each, Table 3$)$. The associations between functional parameters, smoking status, HRQL and educational level are illustrated in Figures 2A-D and Figure 3A-C. In general, never-smokers showed better values than ex-smokers, and higher education was associated with better values independent of smoking status. This was reflected in the absence of significant interaction terms between smoking and education (Table 3). When repeating the analysis excluding all patients with the physician-based diagnosis of asthma, we could confirm all results except for $\mathrm{FVC}$ and $\mathrm{FEV}_{1} / \mathrm{FVC}$. Here, significant associations with education were no longer present.

\section{Relationship Between Comorbidities, Smoking Status and Educational Level}

Table 4 shows the associations between comorbidities, smoking status and educational level found by multiple logistic regression models adjusted for age, sex, and BMI. Never-smokers were more likely to report the diagnoses of asthma, bronchiectasis and alpha-1 antitrypsin deficiency (AATD, $\mathrm{p}<0.05$ each). We found no associations between comorbidities and educational level, except for asthma, which was associated with the highest level, and for AATD, which was associated with secondary education.

\section{Relationship Between Medication, Smoking Status and Educational Level}

When using multiple logistic regression analyses adjusted for age, sex, BMI and $\mathrm{FEV}_{1}$ \%predicted, we found no significant associations between the prescription of medication and smoking status as well as educational level (see Table S1).

\section{Relationship Between Mortality, Smoking Status and Educational Level}

Higher education was associated with a reduced mortality over the follow-up time of 4.5 years (HR 0.46 95\%-CI [0.22-0.98], see Table S2). This was accompanied by associations with age (HR 2.77 95\%-CI [1.94-3.95] for 10 years increase of age) and $\mathrm{FEV}_{1} \%$ predicted (HR for a decrease of $10 \% 1.29$ 95\%-CI [1.12-1.49]). Regarding smoking status, there was only a tendency towards an association with reduced mortality in never-smokers (HR
$0.8495 \%$-CI [0.45-1.60]). Coronary artery disease was not a significant predictor for mortality.

\section{Sensitivity Analyses}

When repeating the analyses stratified according to the duration of ex-smoking (group 1: $10-15$ years, $\mathrm{n}=294$; group 2: $16-25$ years, $n=187$; group $3: \geq 26$ years, $n=135$ ) we confirmed the results for education in all three sub-groups. Regarding the effects of smoking, differences between never-smokers and ex-smokers were maintained in groups 1 and 2, whereas no differences were detected in group 3, ie, patients with the longest time of ex-smoking (see Table S3).

\section{Exclusion of Patients with the Physician-Based Diagnosis of Asthma}

We repeated all analyses excluding the patients with the additional physician-based diagnosis of asthma. All results and the respective tables are provided in Tables S4-S7 and confirmed the previous results. Only the examination of mortality showed that the beneficial effect of higher education was no longer significant $(\mathrm{p}=0.1438)$, however, the direction of the estimate $(\mathrm{HR}=0.52)$ remained unchanged and indicate a lower mortality in the high education group. Due to the now lower number of cases, only $n=58$ cases could be included in the mortality analysis.

\section{Discussion}

In the present study, we compared never-smokers with COPD with long-time ex-smokers with COPD in order to reveal whether, in the absence of the acute challenge of active smoking, these two groups showed different characteristics. Overall, never-smokers showed better functional and clinical characteristics, but the major determinant of differences in both groups was the level of education. In addition to age and lung function, educational level was a major predictor of mortality, in contrast to smoking history. These data suggest benefits on functional and clinical status as well as mortality linked to higher education, which even dominated smoking, if the time of ex-smoking was long.

Spirometric lung function did not differ between neversmokers and ex-smokers, whereas $\mathrm{CO}$ diffusing capacity and indicators of lung hyperinflation/air-trapping showed better values in the never-smokers. In both groups, spirometric lung function but not the other markers depended on education level, with better values for higher education. Since adult and childhood socioeconomic status (SES) are correlated, ${ }^{14}$ it can be assumed that a low socioeconomic status was also present in childhood. Low family SES and low educational level of 
Table I Baseline Characteristics of the Study Sample Stratified by Smoking Status

\begin{tabular}{|c|c|c|c|c|}
\hline \multirow[t]{2}{*}{$\mathbf{n}$} & & \multirow{2}{*}{$\begin{array}{l}\text { Never-Smoker } \\
150\end{array}$} & \multirow{2}{*}{$\begin{array}{l}\text { Ex-Smoker } \\
616\end{array}$} & \multirow[t]{2}{*}{ p-value ${ }^{a}$} \\
\hline & & & & \\
\hline Male & & $70(46.7)$ & $432(70.1)$ & $<0.0001$ \\
\hline Age, yrs & & $68.5 \pm 8.4$ & $68.3 \pm 7.7$ & 0.7268 \\
\hline BMI category ${ }^{b}$ & $\begin{array}{l}\text { Underweight } \\
\text { Normal } \\
\text { Overweight } \\
\text { Obese }\end{array}$ & $\begin{array}{l}4(2.7) \\
65(43.6) \\
54(36.2) \\
26(17.5)\end{array}$ & $\begin{array}{l}10(1.6) \\
201(32.7) \\
265(43.1) \\
139(22.6)\end{array}$ & 0.0531 \\
\hline Education $^{c}$ & $\begin{array}{l}\text { Basic education } \\
\text { Secondary education } \\
\text { Higher education }\end{array}$ & $\begin{array}{l}77(51.3) \\
41(27.3) \\
32(21.3)\end{array}$ & $\begin{array}{l}349(56.7) \\
153(24.8) \\
114(18.5)\end{array}$ & 0.4924 \\
\hline Pulmonary function & $\begin{array}{l}\text { FEV } \% \text { pred } \\
\text { FVC \% pred } \\
\text { FEVI/FVC (L) } \\
\text { TLCO \% pred } \\
\text { KCO \% pred } \\
\text { ITGV \% pred } \\
\text { RV \% pred } \\
\text { RV/TLC } \\
\text { VA \% pred } \\
\text { TLC \% pred }\end{array}$ & $\begin{array}{l}55.2 \pm 18.4 \\
76.8 \pm 19.7 \\
54.9 \pm 10.2 \\
65.2 \pm 25.4 \\
79.5 \pm 29.0 \\
140.8 \pm 31.9 \\
160.1 \pm 45.4 \\
0.55 \pm 0.10 \\
82.8 \pm 16.8 \\
123.5 \pm 35.0\end{array}$ & $\begin{array}{l}53.1 \pm 19.1 \\
78.8 \pm 19.3 \\
51.1 \pm 11.1 \\
57.4 \pm 22.5 \\
67.1 \pm 22.6 \\
146.0 \pm 37.6 \\
167.2 \pm 53.0 \\
0.55 \pm 0.11 \\
84.4 \pm 15.2 \\
115.9 \pm 31.2\end{array}$ & $\begin{array}{l}0.2337 \\
0.2632 \\
\mathbf{0 . 0 0 0 1} \\
\mathbf{0 . 0 0 0 3} \\
<0.0001 \\
0.1208 \\
0.1423 \\
0.6735 \\
0.2719 \\
\mathbf{0 . 0 0 9 5}\end{array}$ \\
\hline GOLD group (mMRC) & $\begin{array}{l}A \\
B \\
C \\
D\end{array}$ & $\begin{array}{l}60(4 I . I) \\
36(24.7) \\
20(13.7) \\
30(20.6)\end{array}$ & $\begin{array}{l}232(37.9) \\
169(27.6) \\
80(\mid 3.1) \\
13 \mid(2 \mid .4)\end{array}$ & 0.8571 \\
\hline Severe exacerbation history & $\begin{array}{l}\text { Proportion Yes } \\
\text { Mean annual rate }\end{array}$ & $\begin{array}{l}24(16.0) \\
1.6 \pm 0.7\end{array}$ & $\begin{array}{l}116(18.9) \\
1.4 \pm 0.8\end{array}$ & $\begin{array}{l}0.4164 \\
0.3806\end{array}$ \\
\hline Years since COPD diagnosis & & $12.3 \pm 9.8$ & $10.7 \pm 7.6$ & 0.0278 \\
\hline AATD & & $34(22.7)$ & $60(9.7)$ & $<0.0001$ \\
\hline Symptoms and Quality of life & $\begin{array}{l}\text { mMRC } \\
\text { SGRQ } \\
\text { activity } \\
\text { symptoms } \\
\text { impacts } \\
\text { CAT } \\
\text { EQ-VAS } \\
\text { EQ-5D utility }\end{array}$ & $\begin{array}{l}1.5 \pm 0.9 \\
42.1 \pm 18.9 \\
55.8 \pm 24.5 \\
54.6 \pm 21.9 \\
29.5 \pm 20.1 \\
17.5 \pm 7.2 \\
56.7 \pm 19.3 \\
0.83 \pm 0.19\end{array}$ & $\begin{array}{l}1.6 \pm 0.9 \\
43.8 \pm 19.9 \\
60.3 \pm 25.7 \\
54.4 \pm 21.1 \\
30.5 \pm 20.6 \\
18.0 \pm 7.2 \\
55.8 \pm 19.6 \\
0.82 \pm 0.19\end{array}$ & $\begin{array}{l}0.1974 \\
0.3238 \\
0.0555 \\
0.9192 \\
0.6065 \\
0.4900 \\
0.6219 \\
0.5629\end{array}$ \\
\hline $\begin{array}{l}\text { PHQ-9 } \\
\text { TUG } \\
\text { IPAQ } \\
6 M W D \\
\text { ABI }\end{array}$ & & $\begin{array}{l}5.66 \pm 3.99 \\
6.76 \pm 2.01 \\
4270.8 \pm 4177.8 \\
434.3 \pm 109.2 \\
1.25 \pm 0.12\end{array}$ & $\begin{array}{l}5.81 \pm 4.36 \\
7.13 \pm 2.59 \\
4373.9 \pm 5947.0 \\
405.3 \pm 108.5 \\
1.19 \pm 0.14\end{array}$ & $\begin{array}{l}0.7002 \\
0.1034 \\
0.8441 \\
\mathbf{0 . 0 0 3 8} \\
<0.0001\end{array}$ \\
\hline
\end{tabular}

Notes: Data are presented as $\mathrm{n}$ (\%) or mean \pm standard deviation. ${ }^{\mathrm{a}} \mathrm{p}$-value based on $\mathrm{Chi}^{2}$-test (categorical variables) and based on ANOVA (continuous variables). ${ }^{\mathrm{b}}$

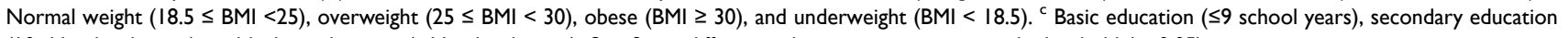
(I0-II school years), and higher education (>II school years). Significant differences between groups are marked in bold $(p<0.05)$. 
Table 2 Mean Household Net Income per Month in Euro by Level of Education

\begin{tabular}{|l|l|l|}
\hline & Mean \pm SD & p-value $^{\mathbf{a}}$ \\
\hline Basic education ( $\leq 9$ years) & $1153 \pm 56 \mathrm{I}$ & $<0.000 \mathrm{I}$ \\
Secondary education (I0-II years) & $1360 \pm 560$ & \\
Higher education (>II years) & $1684 \pm 674$ & \\
\hline
\end{tabular}

Note: ${ }^{a}$ p-value based on ANOVA.

parents have been described as being associated with a higher risk of chronic infections, ${ }^{15}$ which in turn would favour a longterm deterioration of lung function. Furthermore, it can be expected that low socioeconomic status is associated with further lifestyle factors that have a negative effect on lung function, such as air pollution, unhealthy diet, passive smoking and indoor climate. ${ }^{16-18}$ Thus, negative effects on lung function as observed in our study are consistent with previous findings. Our findings are also in accordance with previous investigations showing faster $\mathrm{FEV}_{1}$ decline at least in lesseducated females, independent of smoking. ${ }^{19}$ As potential mechanistic factors, associations between low SES and elevated systemic inflammatory burden have been proposed. ${ }^{20}$

Smoking is known to induce multiple changes in the lung, including alterations in small airways and alveolar structure, ${ }^{21}$ which are reflected in measures of peripheral airway function, in particular hyperinflation/air-trapping and gas exchange capacity. In accordance with this, we found smoking linked to these parameters. It might therefore be speculated, that the peculiar pattern of lung

Table 3 Mean Values of Parameters by Smoking Status and Education

\begin{tabular}{|c|c|c|c|c|c|c|c|c|c|}
\hline & \multicolumn{2}{|c|}{$\begin{array}{l}\text { Basic Education } \\
\text { ( } \leq 9 \text { Years) }\end{array}$} & \multicolumn{2}{|c|}{$\begin{array}{l}\text { Secondary Education } \\
\text { (I0-II Years) }\end{array}$} & \multicolumn{2}{|c|}{$\begin{array}{l}\text { Higher Education } \\
\text { (>I I Years) }\end{array}$} & \multicolumn{2}{|c|}{ Main Effects } & \multirow{2}{*}{$\begin{array}{l}\text { Interaction } \\
\text { Education* } \\
\text { Smoking }\end{array}$} \\
\hline & $\begin{array}{l}\text { Never- } \\
\text { Smoker }\end{array}$ & $\begin{array}{l}\text { Ex- } \\
\text { Smoker }\end{array}$ & $\begin{array}{l}\text { Never- } \\
\text { Smoker }\end{array}$ & $\begin{array}{l}\text { Ex- } \\
\text { Smoker }\end{array}$ & $\begin{array}{l}\text { Never- } \\
\text { Smoker }\end{array}$ & $\begin{array}{l}\text { Ex- } \\
\text { Smoker }\end{array}$ & Education & Smoking & \\
\hline $\mathbf{n}$ & 77 & 349 & 41 & 153 & 32 & 114 & \multicolumn{3}{|l|}{$\mathrm{p}$-value } \\
\hline \multicolumn{10}{|c|}{ Lung function parameters } \\
\hline $\mathrm{FEV}, \%$ pred & 49.3 & 48.7 & 52.3 & 51.2 & 61.3 & 53.0 & 0.0012 & 0.0754 & 0.1958 \\
\hline FVC \% pred & 70.7 & 74.3 & 74.8 & 77.6 & 80.0 & 78.1 & 0.0118 & 0.4347 & 0.4773 \\
\hline FEVI/FVC (L) & 52.9 & 49.6 & 53.4 & 49.9 & 57.8 & 51.3 & 0.0275 & $<0.0001$ & 0.4313 \\
\hline TLCO \% pred & 62.6 & 51.7 & 62.3 & 53.4 & 64.6 & 56.9 & 0.4229 & $<0.0001$ & 0.8178 \\
\hline KCO \% pred & 79.5 & 62.4 & 77.7 & 65.2 & 77.6 & 69.0 & 0.7838 & $<0.0001$ & 0.3492 \\
\hline $\mathrm{RV} / \mathrm{TLC}$ & 0.58 & 0.58 & 0.57 & 0.56 & 0.53 & 0.56 & 0.0096 & 0.3502 & 0.4299 \\
\hline ITGV \% pred & 150.8 & 156.4 & 144.9 & 159.2 & 140.0 & 152.6 & 0.2110 & 0.0021 & 0.4552 \\
\hline RV \% pred & 173.3 & 178.9 & 165.7 & 181.4 & 156.8 & 172.5 & 0.1540 & 0.0140 & 0.5465 \\
\hline VA \% pred & 84.8 & 82.9 & 77.7 & 83.7 & 82.7 & 81.3 & 0.1838 & 0.5704 & 0.0633 \\
\hline TLC \% pred & 122.5 & 123.2 & 125.2 & 123.5 & 113.5 & 118.4 & 0.0490 & 0.6394 & 0.6554 \\
\hline \multicolumn{10}{|c|}{ Symptoms, health-related quality of life, exercise capacity and functioning } \\
\hline SGRQ & 44.5 & 47.3 & 43.0 & 43.2 & 37.8 & 39.5 & $0.008 I$ & 0.4270 & 0.8275 \\
\hline Activity & 60.0 & 65.5 & 58.8 & 60.8 & 44.7 & 55.6 & 0.0001 & 0.0146 & 0.4076 \\
\hline Symptoms & 55.4 & 55.3 & 51.9 & 54.6 & 55.8 & 49.7 & 0.4939 & 0.5973 & 0.3025 \\
\hline Impacts & 31.5 & 33.8 & 30.3 & 29.0 & 27.5 & 26.4 & 0.0571 & 0.9968 & 0.6647 \\
\hline CAT & 18.7 & 19.4 & 18.0 & 17.9 & 16.4 & 17.6 & 0.0518 & 0.4059 & 0.7418 \\
\hline EQ-VAS & 53.9 & 51.4 & 56.1 & 54.0 & 57.7 & 59.3 & 0.0422 & 0.6068 & 0.6610 \\
\hline EQ-5D utility & 0.78 & 0.79 & 0.86 & 0.78 & 0.81 & 0.84 & 0.1229 & 0.3552 & 0.1140 \\
\hline mMRC & 1.59 & 1.76 & 1.65 & 1.67 & 1.42 & 1.50 & 0.1329 & 0.3290 & 0.7365 \\
\hline IPAQ & 3591.4 & 3844.7 & 4111.0 & 3500.6 & 3786.3 & 3857.7 & 0.9847 & 0.8698 & 0.7898 \\
\hline 6MWD & 424.9 & 390.0 & 416.9 & 403.3 & 484.7 & 426.2 & 0.0004 & 0.0007 & 0.2757 \\
\hline $\begin{array}{l}\text { Time up and } \\
\text { go }\end{array}$ & 6.86 & 7.21 & 6.55 & 6.97 & 5.99 & 6.60 & 0.0422 & 0.0615 & 0.9139 \\
\hline PHQ9 & 6.11 & 6.96 & 6.29 & 6.36 & 6.79 & 6.46 & 0.8553 & 0.6406 & 0.4436 \\
\hline$A B I$ & 1.26 & 1.18 & 1.23 & 1.20 & 1.27 & 1.19 & 0.8192 & $<0.0001$ & 0.2178 \\
\hline
\end{tabular}

Notes: Models were adjusted for age, sex, BMI, and time since COPD diagnosis. *marks the interaction between school and smoking. Significant associations are marked in bold $(p<0.05)$. 

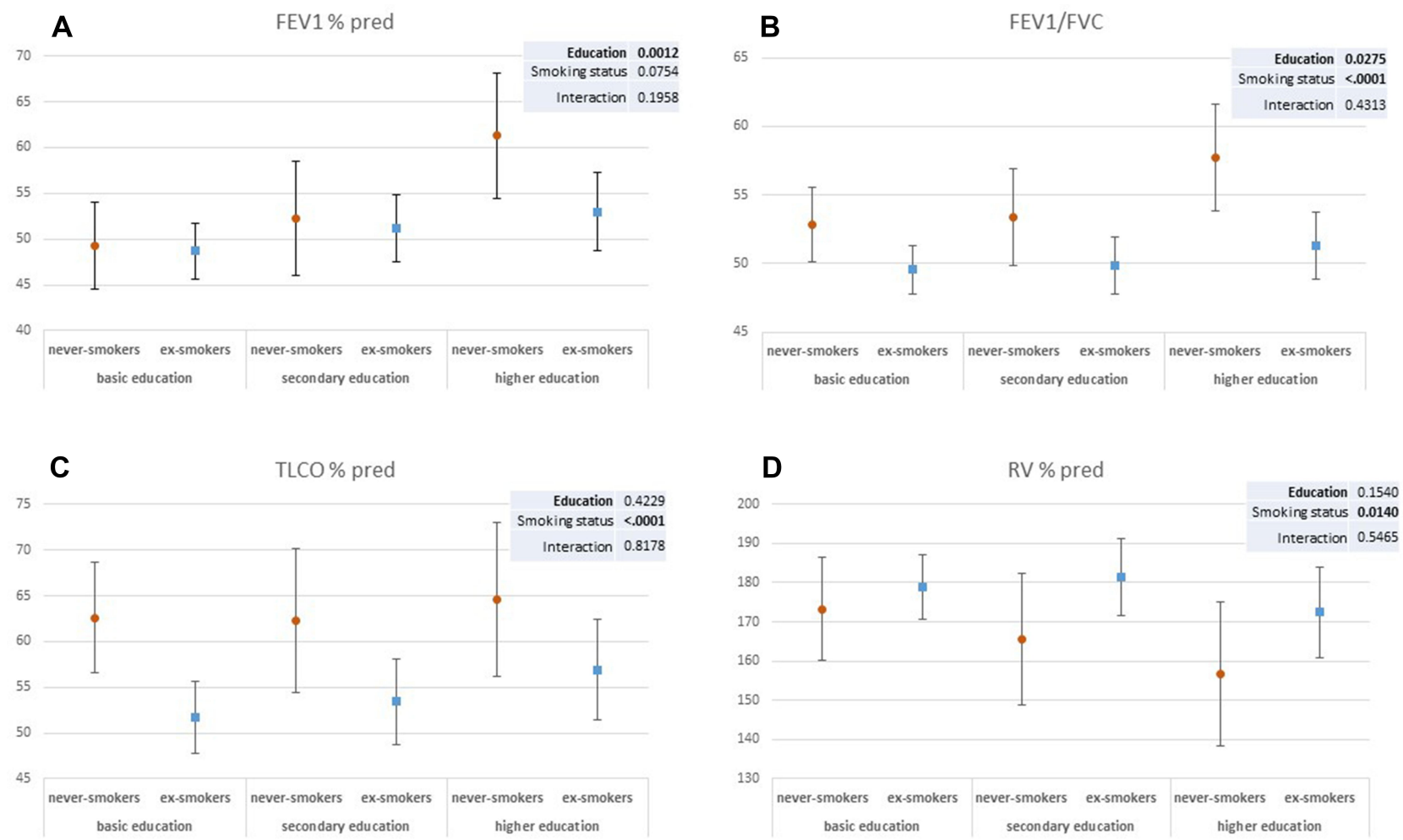

Figure 2 Mean values of lung function parameters by smoking status and by education. Multiple ANOVA models (A-D) were adjusted for age, sex, body mass index (BMI), years since COPD diagnosis, and smoking status*education. Education was categorized as basic education ( $\leq 9$ years), secondary education (10-1I years), and higher education (>II years).

function alteration that we observed reflects differential effects of smoking and socioeconomic history or status as reflected in educational level. In our study population, occupation was part of the socioeconomic status linked to education.

The positive influence of educational level was also reflected in better health-related quality of life and physical capacity, which was true in both never-smokers and exsmokers. Probably, both lung function and life-style factors played a role, in accordance with previous results, ${ }^{22}$ as well as data showing that psychosocial exposures can influence long-term health through mechanisms such as learned behaviour. ${ }^{14}$ For example, the probability of being a smoker or drinker decreases very strongly with higher SES, an accepted proxy for education, ${ }^{14,23,24}$ while at the same time the consumption of healthy diet and the desire for regular physical activity increases. Other studies even found a direct link between lower educational level and decreased physical activity, based on both, material problems and poor perceived health experience. ${ }^{25}$

The association of asthma with educational level has multiple aspects. A low educational level might favour childhood risk factors of asthma, ${ }^{26}$ but a high level also, for example, via the hygiene hypothesis. ${ }^{27}$ The association of asthma with never-smoking could be the result of medical recommendations or early experiences. Moreover, in patients without a history of smoking, physicians may be more inclined to consider asthma, but also bronchiectasis and A1AT deficiency as comorbidity. By contrast, it could be assumed that never-smoker patients are not genuine COPD but asthma patients. To elucidate this, we conducted a sensitivity analysis by excluding patients with the medical record of concomitant asthma. The significant association of education with $\mathrm{FEV}_{1}$ remained essentially unchanged.

We observed no associations of respiratory treatment with the level of education or smoking history, probably as result of unrestricted access to health-care providers and adequate pulmonary treatment. An earlier study in COSYCONET patients showed that the overall treatment adherence was very high, suggesting that the differences found in our study were not due to differences in treatment adherence. ${ }^{28}$ Furthermore, a recent publication in COSYCONET $^{22}$ showed no significant relationship between education and the use of non-pharmacological interventions in COPD including COPD sport programmes and patient 

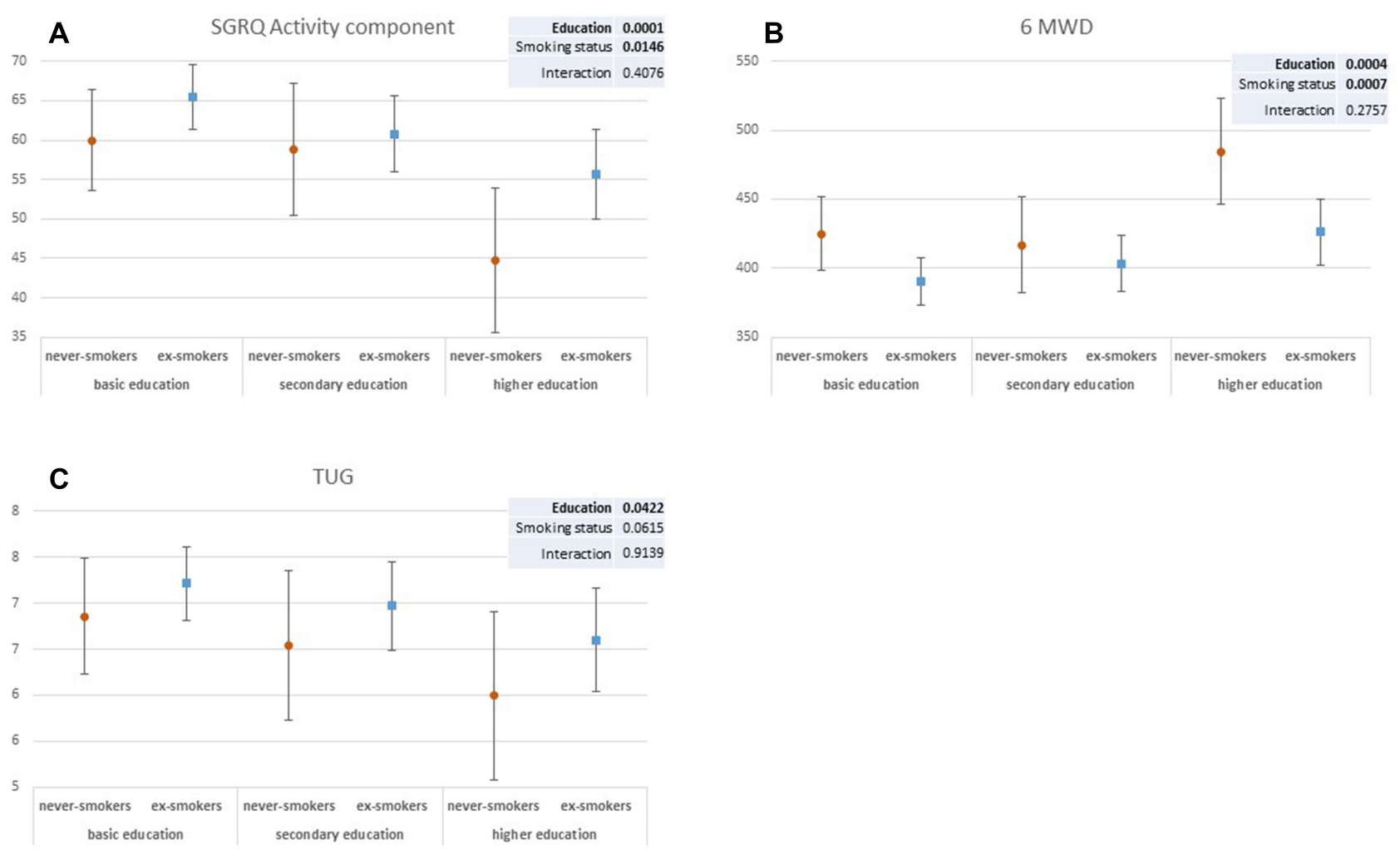

Figure 3 Mean values of health-related quality of life and exercise capacity by smoking status and by education. Multiple ANOVA models (A-C) were adjusted for age, sex, body mass index (BMI), years since COPD diagnosis, and smoking status*education. Education was categorized as basic education ( $\leq 9$ years), secondary education (I0-1I years), and higher education (>II years).

training. We therefore assume that the association between higher education and better lung function is not based on differences in treatment or access to public health care, at least in the cohort studied, which certainly represents a positive selection. Accordingly, it can be concluded that the effect of education on health status can be attributed to the combined risk factors in life history rather than to major differences in the actual treatment of COPD. We included only patients who did not have any burden from cigarette smoke either for a long time or ever. The residual effects from smoking could still be recognized in terms of reductions in gas uptake capacity, which involves changes in both

Table 4 Association Between Comorbidities, Smoking Status, and Education

\begin{tabular}{|c|c|c|c|c|c|}
\hline & \multicolumn{3}{|l|}{ Education } & \multicolumn{2}{|c|}{ Smoking Status } \\
\hline & \multirow[t]{2}{*}{ Basic ( $\leq 9$ Years) } & \multirow{2}{*}{$\begin{array}{l}\text { Secondary (I0-I I Years) } \\
\text { OR }(95 \% \mathrm{CI})\end{array}$} & \multirow{2}{*}{$\begin{array}{l}\text { Higher (> I I Years) } \\
\text { OR }(95 \% \mathrm{CI})\end{array}$} & \multirow[t]{2}{*}{ Ex-Smoker } & Never-Smoker \\
\hline & & & & & OR $(95 \% \mathrm{Cl})$ \\
\hline AATD & ref. & $2.01(1.16-3.47)$ & $1.54(0.84-2.84)$ & ref. & $2.60(1.55-4.37)$ \\
\hline Diabetes & ref. & $0.81(0.47-1.38)$ & $0.69(0.38-1.24)$ & ref. & $1.02(0.57-1.8 I)$ \\
\hline Hypertension & ref. & $1.26(0.87-1.83)$ & $1.08(0.72-1.61)$ & ref. & $0.89(0.6|-| .3 \mid)$ \\
\hline Asthma & ref. & $1.06(0.69-1.63)$ & $1.99(1.28-3.08)$ & ref. & $2.34(1.57-3.49)$ \\
\hline KHK & ref. & $0.76(0.47-1.23)$ & $0.72(0.43-1.20)$ & ref. & $0.75(0.43-1.30)$ \\
\hline Bronchiectasis & ref. & $0.85(0.37-1.96)$ & $1.22(0.54-2.74)$ & ref. & $5.00(2.55-9.8 I)$ \\
\hline Hyperuricemia & ref. & $0.88(0.56-1.40)$ & $0.76(0.46-1.26)$ & ref. & $0.89(0.53-1.48)$ \\
\hline HLP & ref. & $0.92(0.65-1.31)$ & $0.75(0.51-1.10)$ & ref. & $0.91(0.63-1.32)$ \\
\hline Osteoporosis & ref. & $0.69(0.43-1.09)$ & $0.63(0.37-1.08)$ & ref. & $\mathrm{I} .48(0.95-2.3 \mathrm{I})$ \\
\hline GI & ref. & $0.83(0.59-1.18)$ & $0.74(0.50-1.08)$ & ref. & $0.78(0.54-1.13)$ \\
\hline
\end{tabular}

Notes: Logistic regression models were adjusted for age, sex, and BMI (estimates not shown). Significant associations are marked in bold ( $\mathrm{p}<0.05)$. 
ventilation and pulmonary capillary perfusion. In accordance with this, the ankle-brachial index was slightly reduced in exsmokers but not dependent on educational level. As there were no significant differences in cardiovascular comorbidities between never- and ex-smokers, this suggests a differential effect of smoking on cardiovascular status. It could be that the diagnosis of a comorbidity is more difficult in the presence of COPD. ${ }^{29}$ The absence of differences in the prevalence of cardiovascular comorbidities was consistent with the finding that cardiovascular disease was not involved in the prediction of mortality, in contrast to educational level that was predictive even when accounting for $\mathrm{FEV}_{1} \%$ predicted, age, BMI and sex. These observations underlined the major importance of educational level.

\section{Limitations}

Information indicating a previous diagnosis of tuberculosis, which could also be a risk factor for COPD, was given by $n=21$ patients; due to the small sample size, we did not address this topic in our analyses. A number of factors experienced during childhood are known to influence the development of respiratory diseases, but also lung function in adulthood. These include low birth weight, premature birth, repeated respiratory infections in childhood, and prenatal and later exposure to passive smoking. ${ }^{30}$ Such data was not collected in COSYCONET, so that a further evaluation was not possible. SES trajectories, such as downward or upward social mobility, may increase and decrease risk of cardiovascular disease. ${ }^{31}$ In COSYCONET only the last SES was surveyed, but the educational level as achieved at an early age in most cases, could be regarded as long-term indicator of SES, in particular with regard to life-style factors. Lower SES is also associated with poorer living conditions such as increased air pollution. However, a corresponding assessment could not be made as due to data safety restrictions only a three-digit postal code was provided by the patients which does allow for a precise determination of their living conditions, eg, proximity to major roads and a present place of residence does not reveal the respective past living conditions.

\section{Conclusion}

In never-smokers with COPD and ex-smokers since at least 10 years, the educational level, as indicator of socioeconomic status, had an impact on clinical and functional status as well as mortality. In the ex-smokers, residual effects of smoking in terms of air-trapping and gas exchange were still present. It is a reasonable expectation that among COPD patients the proportion of non-smokers, including long-time ex- smokers, will increase. Our findings suggest that in these patients, assessments should include socioeconomic status/ education as cumulative indicator of risk factors in life history independent of smoking. The risk group of low educational status may need special care in disease-management programmes for a more regular monitoring of health status and, if necessary, earlier intervention.

\section{COSYCONET Study-Group}

Andreas, Stefan (Lungenfachklinik, Immenhausen); Bals, Robert (Universitätsklinikum des Saarlandes); Behr, Jürgen and Kahnert, Kathrin (Klinikum der Ludwig-MaximiliansUniversität München); Bewig, Burkhard and Thomas Bahmer (Universitätsklinikum Schleswig Holstein); Buhl, Roland (Universitätsmedizin der Johannes-GutenbergUniversität Mainz); Ewert, Ralf and Stubbe, Beate (Universitätsmedizin Greifswald); Ficker, Joachim H. (Klinikum Nürnberg, Paracelsus Medizinische Privatuniversität Nürnberg); Gogol, Manfred (Institut für Gerontologie, Universität Heidelberg); Grohé, Christian (Ev. Lungenklinik Berlin); Hauck, Rainer (Kliniken Südostbayern AG, Kreisklinik Bad Reichenhall); Held, Matthias and Jany, Berthold (Klinikum Würzburg Mitte gGmbH, Standort Missioklinik); Henke, Markus (Asklepios Fachkliniken München-Gauting); Herth, Felix (Thoraxklinik Heidelberg gGmbH); Höffken, Gerd (Fachkrankenhaus Coswig GmbH); Katus, Hugo A. (Universitätsklinikum Heidelberg); Kirsten, Anne-Marie and Watz, Henrik (Pneumologisches Forschungsinstitut an der Lungenclinic Grosshansdorf GmbH); Koczulla, Rembert and Kenn, Klaus (Schön Klinik Berchtesgadener Land); Kronsbein, Juliane (Berufsgenossenschaftliches Universitätsklinikum Bergmannsheil, Bochum); KropfSanchen, Cornelia (Universitätsklinikum Ulm); Lange, Christoph and Zabel, Peter (Forschungszentrum Borstel); Pfeifer, Michael (Klinik Donaustauf); Randerath, Winfried J. (Wissenschaftliches Institut Bethanien e. V., Solingen); Seeger, Werner (Justus-Liebig-Universität Gießen); Studnicka, Michael (Uniklinikum Salzburg); Taube, Christian and Teschler, Helmut (Ruhrlandklinik gGmbH Essen); Timmermann, Hartmut (Hamburger Institut für Therapieforschung $\mathrm{GmbH})$; Virchow, J. Christian (Universitätsklinikum Rostock); Vogelmeier, Claus (Universitätsklinikum Gießen und Marburg GmbH, Standort Marburg); Wagner, Ulrich (Klinik Löwenstein $\mathrm{gGmbH}$ ); Welte, Tobias (Medizinische Hochschule Hannover); Wirtz, Hubert (Universitätsklinikum Leipzig). 


\section{Names of Participating Study Nurses}

Doris Lehnert, Evangelische Lungenklinik Berlin; Birte Struck, Bergmannsheil Berufsgenossenschaftliches Universitätsklinikum Bochum; Lenka Krabbe, MedizinischeKlinik Borstel; Barbara Arikan, Julia Tobias, Klinik Donaustauf; Gina Spangel, Julia Teng, Ruhrlandklinik gGmbH Essen, Kornelia Speth, Universitätsklinikum Gießen; Jeanette Pieper, Universitätsmedizin Greifswald; Margret Gleiniger, Britta Markworth, Zaklina Hinz, Petra Hundack-Winter, Pneumologisches Forschungsinstitut Großhansdorf; Ellen Burmann, Hamburger Institut für Therapieforschung Hamburg; Katrin Wons, Sylvia Wagner Medizinische Hochschule Hannover; Ulrike Rieber, Beate Schaufler, Thoraxklinik am Universitätsklinikum Heidelberg; Martina Seibert, Universitätsklinikum des Saarlandes, Homburg/Saar; Katrin Schwedler, Lungenfachklinik Immenhausen; Sabine Michalewski, Sonja Rohweder, Universitätsklinikum Schleswig-Holstein, Campus Kiel; Patricia Berger, Universitätsklinikum Leipzig; Diana Schottel, Krankenhaus Lindenbrunn, Coppenbrügge; Manuel Klöser, Universitätsmedizin der Johannes GutenbergUniversität Mainz; Vivien Janke, Universitätsklinikum Marburg; Rosalie Untsch, Asklepios Fachkliniken, MünchenGauting; Jana Graf, Klinikum der Universität München; Anita Reichel, Klinikum Nürnberg; Gertraud Weiß, Erich Traugott, Barbara Ziss, Schön Klinik Berchtesgadener Land; Ilona Kietzmann, Wissenschaftliches Institut Bethanien für Pneumologie e. V, Solingen; Michaela Schrade-Illmann, Beate Polte, Universitätsklinikum-Ulm; Cornelia Böckmann, Gudrun Hübner, Lena Sterk, Anne Wirz, Klinikum Würzburg Mitte gGmbH, Standort Missioklinik, Würzburg.

\section{Data Sharing Statement}

The basic data are part of the German COPD cohort COSYCONET (www.asconet.net/) and available upon request. There is a detailed procedure for this on the website of this network. Specifically, the data can be obtained by submission of a proposal which is evaluated by the steering committee. All results to which the manuscript refers to are documented by the appropriate in the text, figures or tables.

\section{Ethics Approval and Consent to Participate}

All assessments were approved by the central (Marburg (Ethikkommission FB Medizin Marburg) and local (Bad Reichenhall (Ethikkommission bayerische Landesärztekammer); Berlin (Ethikkommission Ärztekammer Berlin);
Bochum (Ethikkommission Medizinische Fakultät der RUB); Borstel (Ethikkommission Universität Lübeck); Coswig (Ethikkommission TU Dresden); Donaustauf (Ethikkommission Universitätsklinikum Regensburg); Essen (Ethikkommission Medizinische Fakultät Duisburg-Essen); Gießen (Ethikkommission Fachbereich Medizin); Greifswald (Ethikkommission Universitätsmedizin Greifswald); Großhansdorf (Ethikkommission Ärztekammer SchleswigHolstein); Hamburg (Ethikkommission Ärztekammer Hamburg); MHH Hannover/Coppenbrügge (MHH Ethikkommission); Heidelberg Thorax/Uniklinik (Ethikkommission Universität Heidelberg); Homburg (Ethikkommission Saarbrücken); Immenhausen (Ethikkommission Landesärztekammer Hessen); Kiel (Ethikkommission ChristianAlbrechts-Universität zu Kiel); Leipzig (Ethikkommission Universität Leipzig); Löwenstein (Ethikkommission Landesärztekammer Baden-Württemberg); Mainz (Ethikkommission Landesärztekammer Rheinland-Pfalz); München LMU/Gauting (Ethikkommission Klinikum Universität München); Nürnberg (Ethikkommission Friedrich-AlexanderUniversität Erlangen Nürnberg); Rostock (Ethikkommission Universität Rostock); Berchtesgadener Land (Ethikkommission Land Salzburg); Schmallenberg (Ethikkommission Ärztekammer Westfalen-Lippe); Solingen (Ethikkommission Universität Witten-Herdecke); Ulm (Ethikkommission Universität Ulm); Würzburg (Ethikkommission Universität Würzburg)) ethical committees and written informed consent was obtained from all patients.

The study comprised 2270 patients recruited within the COSYCONET framework (ClinicalTrials.gov, Identifier: NCT01245933).

For further information see:

Karch A, Vogelmeier C, Welte T, Bals R, Kauczor HU, Biederer J, Heinrich J, Schulz H, Glaser S, Holle R et al: The German COPD cohort COSYCONET: Aims, methods and descriptive analysis of the study population at baseline. Respir Med 2016, 114:27-37. ${ }^{1}$

\section{Consent for Publication}

Within the ethical approval the participants of the study gave their consent to publish the data collected during the study period.

\section{Acknowledgments}

We would like to thank all patients for their kind participation as well as the COSYCONET Study-Group and the participating study nurses for their efforts. 


\section{Author Contributions}

All authors made substantial contributions to conception and design, acquisition of data, or analysis and interpretation of data; took part in drafting the article or revising it critically for important intellectual content; agreed on the journal to which the article will be submitted; gave final approval of the version to be published; and agree to be accountable for all aspects of the work.

\section{Funding}

This work is supported by the German Centre for Lung Research (DZL), grant number 82DZLI05A2 (COSYCONET), the BMBF, grant number 01GI0881 and is furthermore supported by unrestricted grants from AstraZeneca $\mathrm{GmbH}$, Boehringer Ingelheim Pharma $\mathrm{GmbH}$ \& Co. KG, GlaxoSmithKline GmbH\&Co. KG, Grifols Deutschland $\mathrm{GmbH}$, and Novartis Deutschland GmbH.

\section{Disclosure}

Johanna I Lutter reports grants from German Federal Ministry of Education and Research (BMBF) with grant number 01GI0882, during the conduct of the study. Tobias Welte reports grants from German Ministry of Research and Education, during the conduct of the study. Rolf Holle reports grants from German Federal Ministry of Education and Research, during the conduct of the study. Dr. Vogelmeier stated the follwoing:Relevant financial activities outside the submitted work:Grants from AstraZeneca, Boehringer Ingelheim, Chiesi, GlaxoSmithKline, Grifols, Novartis and German Federal Ministry of Education and Research (BMBF) Competence Network Asthma und COPD (ASCONET). Furthermore, Dr. Vogelmeier reported personal fees from Astra Zeneca, Boehringer Ingelheim, Chiesi, GlaxoSmithKline, Grifols, Novartis, Berlin Chemie/ Menarini, CSL Behring, Nuvaira, MedUpdate. Kathrin Kahnert reports personal fees from Novartis $\mathrm{GmbH}$, outside the submitted work. The authors report no other potential conflicts of interest for this work.

\section{References}

1. Karch A, Vogelmeier C, Welte T, et al. The German COPD cohort COSYCONET: aims, methods and descriptive analysis of the study population at baseline. Respir Med. 2016;114:27-37. doi:10.1016/j. rmed.2016.03.008

2. Helmert U, Mielck A, Shea S. Poverty and health in West Germany. Sozial- und Präventivmedizin SPM. 1997;42(5):276-285. doi:10.1007/ BF01592324
3. Lucke T, Herrera R, Wacker M, et al. Systematic Analysis of SelfReported Comorbidities in Large Cohort Studies - A Novel Stepwise Approach by Evaluation of Medication. PLoS One. 2016;11(10): e0163408. doi:10.1371/journal.pone.0163408

4. Stanojevic S, Graham BL, Cooper BG, et al. Official ERS technical standards: global Lung Function Initiative reference values for the carbon monoxide transfer factor for Caucasians. Eur Respir J. 2017;50(3):3. doi:10.1183/13993003.00010-2017

5. Celli BR, Decramer M, Wedzicha JA, et al. An Official American Thoracic Society/European Respiratory Society Statement: research questions in chronic obstructive pulmonary disease. Am J Respir Crit Care Med. 2015;191(7):e4. doi:10.1164/rccm.201501-0044ST

6. Criee CP, Baur X, Berdel D, et al. [Standardization of spirometry: 2015 update. Published by German Atemwegsliga, German Respiratory Society and German Society of Occupational and Environmental Medicine]. Pneumologie. 2015;69(3):147-164. German.

7. van der Lee I, Zanen P, Stigter N, van den Bosch JM, Lammers J-WJ. Diffusing capacity for nitric oxide: reference values and dependence on alveolar volume. Respir Med. 2007;101(7):1579-1584. doi:10.1016/j.rmed.2006.12.001

8. Quanjer PH, Tammeling GJ, Cotes JE, Pedersen OF, Peslin R, Yernault J-C. Lung volumes and forced ventilatory flows. Eur Respir J. 1993;6(Suppl 16):5-40. doi:10.1183/09041950.005s 1693

9. Hagstromer M, Oja P, Sjostrom M. The International Physical Activity Questionnaire (IPAQ): a study of concurrent and construct validity. Public Health Nutr. 2006;9(6):755-762. doi:10.1079/PHN2005898

10. Houben-Wilke S, Jorres RA, Bals R, et al. Peripheral Artery Disease and Its Clinical Relevance in Patients with Chronic Obstructive Pulmonary Disease in the COPD and Systemic Consequences-Comorbidities Network Study. Am J Respir Crit Care Med. 2017;195(2):189-197.

11. Jones PW, Quirk FH, Baveystock CM, Littlejohns P. A Self-complete Measure of Health Status for Chronic Airflow Limitation: the St. George's Respiratory Questionnaire. Am Rev Respir Dis. 1992;145(6):1321-1327. doi:10.1164/ajrccm/145.6.1321

12. Greiner W, Claes C, Busschbach JJ, Graf von der Schulenburg J-M. Validating the EQ-5D with time trade off for the German population. Eur J Health Econ. 2005;6(2):124-130. doi:10.1007/s10198-004-0264-z

13. Waschki B, Alter P, Zeller T, et al. High-sensitivity troponin I and all-cause mortality in patients with stable COPD: an analysis of the COSYCONET study. Eur Respir J. 2020;55(2):2. doi:10.1183/ 13993003.01314-2019

14. Cohen S, Janicki-Deverts D, Chen E, Matthews KA. Childhood socioeconomic status and adult health. Ann $N$ Y Acad Sci. 2010;1186(1):37-55. doi:10.1111/j.1749-6632.2009.05334.x

15. Dowd JB, Zajacova A, Aiello A. Early origins of health disparities: burden of infection, health, and socioeconomic status in U.S. children. Soc Sci Med. 2009;68(4):699-707. doi:10.1016/j. socscimed.2008.12.010

16. Hegewald MJ, Crapo RO. Socioeconomic status and lung function. Chest. 2007;132(5):1608-1614. doi:10.1378/chest.07-1405

17. Mannino DM, Buist AS. Global burden of COPD: risk factors, prevalence, and future trends. Lancet. 2007;370(9589):765-773. doi:10.1016/S0140-6736(07)61380-4

18. Prescott E, Vestbo J. Socioeconomic status and chronic obstructive pulmonary disease. Thorax. 1999;54(8):737-741. doi:10.1136/ thx.54.8.737

19. Tabak C, Spijkerman AM, Verschuren WM, Smit HA. Does educational level influence lung function decline (Doetinchem Cohort Study)? Eur Respir J. 2009;34(4):940-947. doi:10.1183/09031936.00111608

20. Pollitt RA, Kaufman JS, Rose KM, Diez-Roux AV, Zeng D, Heiss G. Cumulative life course and adult socioeconomic status and markers of inflammation in adulthood. $J$ Epidemiol Community Health. 2008;62(6):484-491. doi:10.1136/jech.2006.054106 
21. Cosio MG, Hale KA, Niewoehner DE. Morphologic and morphometric effects of prolonged cigarette smoking on the small airways. Am Rev Respir Dis. 1980;122(2):265.

22. Lutter JI, Jorres RA, Kahnert K, et al. Health-related quality of life associates with change in FEV1 in COPD: results from the COSYCONET cohort. BMC Pulm Med. 2020;20(1):148. doi:10.1186/s12890-020-1147-5

23. Barbeau EM, Krieger N, Soobader M-J. Working class matters: socioeconomic disadvantage, race/ethnicity, gender, and smoking in NHIS 2000. Am J Public Health. 2004;94(2):269-278. doi:10.2105/ AJPH.94.2.269

24. Pryer JA. Dietary patterns among a national random sample of British adults. J Epidemiol Community Health. 2001;55(1):29-37. doi: $10.1136 /$ jech.55.1.29

25. Droomers M. Educational level and decreases in leisure time physical activity: predictors from the longitudinal GLOBE study. J Epidemiol Community Health. 2001;55(8):562-568. doi:10.1136/jech.55.8.562

26. Eagan TML, Gulsvik A, Eide GE, Bakke PS. The effect of educational level on the incidence of asthma and respiratory symptoms. Respir Med. 2004;98(8):730-736. doi:10.1016/j.rmed.2004.02.008

27. Uphoff E, Cabieses B, Pinart M, Valdes M, Anto JM, Wright J. A systematic review of socioeconomic position in relation to asthma and allergic diseases. Eur Respir J. 2015;46(2):364-374. doi:10.1183/09031936.00114514
28. Konigsdorfer N, Jorres RA, Sohler S, et al. $<\mathrm{p}>$ Adherence To Respiratory And Nonrespiratory Medication In Patients With COPD: results Of The German COSYCONET Cohort. Patient Prefer Adherence. 2019;13:1711-1721. doi:10.2147/PPA.S223438

29. Alter P, Mayerhofer BA, Kahnert K, et al. $<\mathrm{p}>$ Prevalence of cardiac comorbidities, and their underdetection and contribution to exertional symptoms in COPD: results from the COSYCONET cohort. Int J Chron Obstruct Pulmon Dis. 2019;14:2163-2172. doi:10.2147/COPD.S209343

30. Stick S. Paediatric origins of adult lung disease bullet 1: the contribution of airway development to paediatric and adult lung disease. Thorax. 2000;55(7):587-594. doi:10.1136/thorax.55.7.587

31. Hallqvist J, Lynch J, Bartley M, Lang T, Blane D. Can we disentangle life course processes of accumulation, critical period and social mobility? An analysis of disadvantaged socio-economic positions and myocardial infarction in the Stockholm Heart Epidemiology Program. Soc Sci Med. 2004;58(8):1555-1562. doi:10.1016/S02779536(03)00344-7

32. Centers for Disease Control and Prevention. Cigarette smoking among adults-United States. MMWR Morb Mortal Wkly Rep. 2008;57:1221-1226.

\section{Publish your work in this journal}

The International Journal of COPD is an international, peer-reviewed journal of therapeutics and pharmacology focusing on concise rapid reporting of clinical studies and reviews in COPD. Special focus is given to the pathophysiological processes underlying the disease, intervention programs, patient focused education, and self management protocols. This journal is indexed on PubMed Central, MedLine and CAS. The manuscript management system is completely online and includes a very quick and fair peer-review system, which is all easy to use. Visit http://www.dovepress.com/testimonials.php to read real quotes from published authors. 